\title{
Effects of Prolonged Hyperinsulinemia on Serum Leptin in Normal Human Subjects
}

\author{
Guenther Boden, ${ }^{\star}$ Xinhua Chen, ${ }^{\star}$ Jerzy W. Kolaczynski, ${ }^{\ddagger}$ and Marcia Polansky ${ }^{\S}$ \\ *Division of Endocrinology/Diabetes/Metabolism and the General Clinical Research Center, Temple University School of Medicine; \\ ${ }^{\ddagger}$ Thomas Jefferson University Hospital; and ${ }^{\S}$ Allegheny University of the Health Sciences, Philadelphia, Pennsylvania 19140
}

\begin{abstract}
We have studied the effect of prolonged hyperinsulinemia and hyperglycemia on serum leptin levels in young nonobese males during 72-h euglycemic-hyperinsulinemic and hyperglycemic $(\sim 8.5$ and $12.6 \mathrm{mM})$ clamps. Hyperinsulinemia increased serum leptin concentrations (by RIA) dosedependently. An increase in serum insulin concentration of $>200 \mathrm{pM}$ for $>24 \mathrm{~h}$ was needed to significantly increase serum leptin. An increase of $\sim 800 \mathrm{pM}$ increased serum leptin by $\sim 70 \%$ over $72 \mathrm{~h}$. Changes in plasma glucose concentrations (from $\sim 5.0$ to $\sim 12.6 \mathrm{mM}$ ) or changes in plasma FFA concentrations (from $<100$ to $>1,000 \mu \mathrm{M}$ ) had no effect on serum leptin. Serum leptin concentrations changed with circadian rhythmicity. The cycle length was $\sim 24 \mathrm{~h}$, and the cycle amplitude (peak to trough) was $\sim 50 \%$. The circadian leptin cycles and the circadian cycles of total body insulin sensitivity (i.e., GIR, the glucose infusion rates needed to maintain euglycemia during hyperinsulinemic clamping) changed in a mirror image fashion. Moreover, GIR decreased between Days 2 and 3 (from 11.4 \pm 0.2 to $9.8 \pm 0.2 \mathrm{mg} / \mathrm{kg} \mathrm{min}, P<0.05)$ when mean $24-\mathrm{h}$ leptin levels reached a peak. In summary, we found (a) that $72 \mathrm{~h}$ of hyperinsulinemia increased serum leptin levels dose-dependently; (b) that hyperglycemia or high plasma FFA levels did not affect leptin release; (c) that leptin was released with circadian rhythmicity, and (d) that 24-h leptin cycles correlated inversely with 24-h cycles of insulin sensitivity. We speculate that the close positive correlation between body fat and leptin is mediated, at least in part, by insulin. $(J$. Clin. Invest. 1997. 100:1107-1113.) Key words: hyperglycemia - free fatty acids - circadian leptin release $\bullet$ insulin resistance
\end{abstract}

\section{Introduction}

Leptin, the ob gene product, is a $16-\mathrm{kD}$ protein that is synthesized and released from white adipose tissue $(1,2)$. When given to leptin-deficient ob/ob mice and to wild-type obese

Address correspondence to Guenther Boden, M.D., Temple University Hospital, 3401 North Broad Street, Philadelphia, PA 19140. Phone: 215-707-8984; FAX: 215-707-1560.

Received for publication 24 February 1997 and accepted in revised form 10 June 1997.

J. Clin. Invest.

(C) The American Society for Clinical Investigation, Inc. 0021-9738/97/09/1107/07 \$2.00

Volume 100, Number 5, September 1997, 1107-1113

http://www.jci.org mice, leptin decreased food intake and increased caloric expenditure and weight loss (2-4). Moreover, it has been established that serum leptin levels correlated positively with adipose tissue mass $(5,6)$. Based on these observations, it has been postulated that leptin is a signal from the adipose tissue to the brain where it may act as a regulator of body fat mass. Whether leptin plays a similar role in human appetite regulation and weight control is unclear. Also, there is currently little information on what controls leptin secretion in humans. It has become clear, however, that factors other than changes in adipose tissue mass must be involved. For instance, it has recently been shown in human subjects that fasting for $24-52 \mathrm{~h}$ produced dramatic decreases in serum leptin concentrations $(>50 \%)$, which could not be explained by changes in adipose tissue mass $(7,8)$. Possible causes for the precipitous decrease in leptin during fasting include changes in serum insulin and/or glucose concentrations. Insulin, because of its close relationship to appetite and body weight control (9), has been scrutinized by several groups (10-16). All but one (16) found no acute (up to $5 \mathrm{~h}$ ) effects of hyperinsulinemia on serum leptin concentrations. As leptin's role is likely to be that of a long-term adiposity signal, information on effects of prolonged hyperinsulinemia on leptin release would be of interest. It was, therefore, the objective of this study to assess the effects of prolonged $(72 \mathrm{~h})$ changes in serum insulin and glucose levels on plasma leptin concentration in healthy nonobese subjects.

\section{Methods}

Subjects. 28 healthy normal weight males were studied with five different study protocols. The subjects ages, weights, heights, body mass indices (BMI), ${ }^{1}$ and body fat are shown in Table I. There were not statistically significant differences in age, height, weight, percent fat, or BMI among groups. Their body weights were stable for at least $2 \mathrm{mo}$, and their diets contained a minimum of $250 \mathrm{~g} / \mathrm{d}$ of carbohydrate for at least $2 \mathrm{~d}$ before the studies. Informed written consent was obtained from all subjects after explanation of the nature, purpose, and potential risks of these studies. The study protocols were approved by the Institutional Review Board of Temple University Hospital.

\section{Experimental design}

All subjects were admitted to Temple University Hospital's General Clinical Research Center on the evening before the studies. The studies began between 8 and $10 \mathrm{AM}$ after an overnight fast, with the subjects reclining in bed. A short polyethylene catheter was inserted into an antecubital vein for infusion of glucose. A second catheter was placed into a contralateral forearm vein for blood sampling. This arm was wrapped with a heating blanket $\left(\sim 70^{\circ} \mathrm{C}\right)$ to arterialize venous blood. Five different experimental protocols were used.

1. Abbreviations used in this paper: BMI, body mass index; GIR, glucose infusion rate. 


\begin{tabular}{|c|c|c|c|c|c|c|}
\hline Protocol & Glucose level & Age & Height & Weight & Fat & BMI \\
\hline & & $y r$ & $\mathrm{~cm}$ & $\mathrm{~kg}$ & $\%$ & $\mathrm{~kg} / \mathrm{m}^{2}$ \\
\hline 1 & $\sim 5.0 \mathrm{mM}(n=5)$ & $\begin{array}{c}31.7 \pm 7.2 \\
\text { NS }\end{array}$ & $\begin{array}{c}174.0 \pm 7.4 \\
\mathrm{NS}\end{array}$ & $\begin{array}{c}78.6 \pm 10.8 \\
\text { NS }\end{array}$ & $\begin{array}{c}16.6 \pm 6.6 \\
\text { NS }\end{array}$ & $\begin{array}{c}25.8 \pm 2.0 \\
\text { NS }\end{array}$ \\
\hline 2 & $\sim 5.0 \mathrm{mM}(n=5)(+$ insulin $)$ & $39.8 \pm 2.8$ & $180.2 \pm 3.9$ & $74.4 \pm 6.2$ & $18.0 \pm 4.0$ & $22.8 \pm 1.3$ \\
\hline 3 & $\sim 8.5 \mathrm{mM}(n=5)$ & $\begin{array}{c}32.6 \pm 3.3 \\
\text { NS }\end{array}$ & $\begin{array}{c}182.6 \pm 3.3 \\
\text { NS }\end{array}$ & $\begin{array}{c}87.1 \pm 7.5 \\
\text { NS }\end{array}$ & $\begin{array}{c}16.1 \pm 3.7 \\
\text { NS }\end{array}$ & $\begin{array}{c}26.2 \pm 1.8 \\
\text { NS }\end{array}$ \\
\hline 4 & $\sim 8.5 \mathrm{mM}(n=6)(+$ lipid/heparin $)$ & $29.0 \pm 4.1$ & $179.6 \pm 2.9$ & $75.0 \pm 2.0$ & $10.8 \pm 0.6$ & $23.4 \pm 0.4$ \\
\hline 5 & $\sim 12.6 \mathrm{mM}(n=7)$ & $37.6 \pm 1.6$ & $179.0 \pm 4.2$ & $84.2 \pm 3.0$ & $17.1 \pm 1.9$ & $26.4 \pm 0.5$ \\
\hline
\end{tabular}

NS, not significant $(P>0.05)$.

Protocol 1: euglycemic clamp $(n=5)$. A $5 \%$ glucose solution was infused intravenously at a variable rate that was adjusted as needed to maintain plasma glucose at or near $5 \mathrm{mM}$ for $72 \mathrm{~h}$.

Protocol 2: hyperinsulinemic-euglycemic clamp $(n=5)$. Regular human insulin (Humulin R; Eli Lilly and Co., Indianapolis, IN) was infused intravenously at a rate of $12 \mathrm{pmol} / \mathrm{kg} \min$ for $72 \mathrm{~h}$, and plasma glucose concentrations were clamped at $\sim 5 \mathrm{mM}$ by a feedback-controlled glucose infusion. In this and in all other studies, the volunteers were allowed to drink water, but otherwise received no calories by mouth and remained at bedrest for the duration of the study.

Protocol 3: hyperglycemic clamps $(\sim 8.5 \mathrm{mM}, n=5)$. Glucose was infused at variable rates to maintain plasma glucose at between 8 and $9 \mathrm{mM}$ for $48 \mathrm{~h}$. Plasma electrolytes were monitored every $6 \mathrm{~h}$, body weight was checked every $12 \mathrm{~h}$, and fluid balance was checked every $6 \mathrm{~h}$. Fluid balance was maintained with infusion of normal saline. Potassium and magnesium were added to the glucose infusion as needed to maintain normal plasma concentrations.

Protocol 4: hyperglycemic clamps $(\sim 8.5 \mathrm{mM})$ with lipid/heparin infusion, $(n=6)$. Glucose was infused as in Protocol 3. In addition, fat (Liposyn II; Abbott Laboratories Diagnostic Division, Chicago, IL) was infused at a rate of $4.3 \mu \mathrm{mol} / \mathrm{kg}$ min together with heparin (0.4 U/kg min).

Protocol 5: hyperglycemic clamps $(\sim 12.6 \mathrm{mM}, n=7)$. Variable glucose infusion rates were used to maintain plasma glucose at 12-13 $\mathrm{mM}$ for $72 \mathrm{~h}$. Plasma glucose was monitored, and infusion rates were adjusted every hour or more frequently when needed. Fluid balance, weight, and electrolytes were monitored and maintained as in Protocol 3 .

\section{Analytical methods}

Plasma glucose was measured with a glucose analyzer (Beckman Instruments, Inc., Fullerton, CA); serum free insulin was determined by radioimmunoassay with an antiserum with minimal $(<0.2 \%)$ crossreactivity with proinsulin (Linco Research Inc., St. Charles, MO). Leptin was measured with a radioimmunoassay with a kit (Linco Research Incorporated). Plasma FFA were measured enzymatically with a kit (Wako Bioproducts, Richmond, VA). Diethyl $p$-nitro-phenyl phosphate (Paroxam; Sigma Chemical Co., St. Louis, MO) was added to all tubes to prevent in vitro lipolysis. Body composition was determined with bioelectrical impedance analysis (17).

\section{Statistical analysis and analysis of periodicity}

All results are shown as mean \pm SE. Multivariate analysis of variance with repeated measures was used to determine changes in substrate and hormone concentrations over time and between groups. Student's $t$ test was used to analyze differences between groups at specific time points. Linear regression analysis was used to determine the relationship between leptin and other variables. Spectral analysis and the autocorrelation function were used to determine periodicity in se- rum leptin levels $(18,19)$. The spectrum was calculated using a mixed radix fast Fourier transform algorithm. A split cosine bell taper was used to taper $10 \%$ of the series at each end. ANOVA of the fitted Fourier series model was used to test for statistical significance of sinusoidal components. The mean percent changes in leptin levels from baseline measured at 2-h intervals were analyzed. Least squares regression was used to detrend the data before performing the above time series analyses. The statistical software package S-PLUS (Math Soft, Inc., Seattle, WA) was used to perform the Spectral and Fourier analyses.

\section{Results}

Hyperinsulinemia vs. leptin and glucose infusion rates (GIR) (Fig. 1). Plasma glucose was clamped at euglycemic levels (5.4 \pm 0.06 and $5.0 \pm 0.03 \mathrm{mM}$, respectively) while serum insulin was maintained at either basal $(67 \pm 2 \mathrm{pM}, \mathrm{CV} 11 \%)$ or at high $(878 \pm 27 \mathrm{pM}$, coefficient of variation $7.7 \%$ ) levels. At basal insulin concentrations, serum leptin remained essentially unchanged (except for some diurnal fluctuations). In contrast, high insulin concentrations were associated with rising serum leptin levels.

Of interest was the observation that the circadian fluctuations in leptin levels were mirror images of circadian fluctuation in total body insulin sensitivity, as GIR (reflecting insulin sensitivity) rose whenever leptin levels decreased and vice versa. Moreover, mean 24-h GIR remained unchanged until day 3, when it decreased significantly (from $11.4 \pm 0.2$ to $9.8 \pm 0.3 \mathrm{mg} / \mathrm{kg} \mathrm{min}, P<0.05)$ at the same time when mean $24-\mathrm{h}$ leptin levels reached their peak.

Circadian rhythmicity of leptin (Fig. 2). The increase in serum leptin during hyperinsulinemia was clearly cyclical. As can be seen upon inspection of the raw data and the detrended data, there appeared to be a marked 24-h cycle in leptin levels that fell to their lowest levels in the early afternoon and reached peak levels $\sim 12 \mathrm{~h}$ later in the early morning hours. The autocorrelation became negative for lags of 8-16 h, and then became positive again for lags of $18-24 \mathrm{~h}$, indicating that leptin levels were similar at the same hour of each day, but varied during the course of the day. Spectral analysis showed a statistically significant $(P<0.05)$ spectral density at a frequency of $2 / 24$. Frequency is the number of cycles expressed as a proportion of the number of measurements (i.e, the numerator is 2 and the denominator is 24 because a 24 -h cycle would occur twice with blood sampling every $2 \mathrm{~h}$ for $48 \mathrm{~h}$ ). Together, 
the data demonstrated that there was a statistically significant leptin cycle of $\sim 24 \mathrm{~h}$.

Hyperglycemia vs. leptin (Fig. 3). In these experiments, plasma glucose was clamped at basal $(\sim 5.0 \mathrm{mM})$ or high $(\sim 12.6 \mathrm{mM})$ concentrations for $72 \mathrm{~h}$, while serum insulin concentrations were maintained at comparable high levels $(878 \pm 27$ and $765 \pm 36 \mathrm{pM})$. Under those conditions, serum leptin levels rose similarly regardless of whether plasma glucose concentrations were basal or high, indicating that changes in plasma glucose levels did not affect leptin release.

FFA vs. leptin (Fig. 4). We next investigated the possibility that the observed effects of hyperinsulinemia on leptin were mediated by changes in plasma FFA concentrations, which are known to be very sensitive to changes in insulin levels. In these studies, plasma FFA concentrations were maintained at either high $(>1,000 \mu \mathrm{M})$ or a low $(<100 \mu \mathrm{M})$ levels for $48 \mathrm{~h}$ while glucose and insulin concentrations were clamped at $\sim 8.5 \mathrm{mM}$ and at $\sim 200 \mathrm{pM}$, respectively. The results showed that under these conditions, even large increases in plasma FFA levels had no effect on serum leptin concentrations. Serum insulin levels rose transiently (by $\sim 400 \mathrm{pM}$ for $\sim 10 \mathrm{~h}$ ) during the high FFA study. This period of hyperinsulinemia was apparently not long enough to affect serum leptin levels.

Quantitation of the insulin effect on leptin (Fig. 5). To circumvent the problems posed by the cyclical nature of serum leptin levels, we determined mean $24 \mathrm{~h}$ minus leptin changes (mean $24 \mathrm{~h}$ minus basal leptin concentrations) and correlated these values with changes in insulin concentrations (mean $24 \mathrm{~h} \mathrm{mi-}$ nus basal insulin concentration). As seen in Fig. 5, during the first $24 \mathrm{~h}$, rising insulin concentrations were associated with a slight but statistically nonsignificant increase in serum leptin. During days 2 and 3, however, there were highly significant positive correlations between changes in serum leptin and insulin. Fig. 5 (bottom) shows overall changes in serum leptin after $3 \mathrm{~d}$ (mean of day 3 minus basal leptin). Analysis of the linear regression equation in Fig. 5 (bottom) and the data in Figs. 1 and 3 revealed that an increase in serum insulin of $\sim 800 \mathrm{pM}$ was associated with an increase in serum leptin concentration of $\sim 70 \%$ over $3 \mathrm{~d}$, that no changes in serum leptin occurred when insulin increased by $<200 \mathrm{pM}$, while maintenance of basal insulin levels $(\sim 70 \mathrm{pM})$ resulted in a slight decrease in serum leptin $(\sim-15 \%)$.

\section{Discussion}

Prolonged hyperinsulinemia stimulates leptin release. The present study demonstrated that $3 \mathrm{~d}$ of hyperinsulinemia increased serum leptin levels in healthy volunteers, while hyperglycemia was ineffective. The evidence for this can be summarized as follows: first, serum leptin increased only when euglycemia was associated with high, but not with basal insulin concentrations (see Fig. 1). Second, during comparable hyperinsulinemia, serum leptin levels rose equally regardless of whether glucose concentrations were high or basal; and lastly, the increase in serum leptin during combined hyperinsulinemia/hyperglycemia (protocol 5) was the same as the increase during euglycemic hyperinsulinemia (protocol 2). Assuming that insulin did not affect leptin clearance, for which there is some evidence (20), the data indicated that prolonged hyperinsulinemia stimulated leptin secretion independent of hyperglycemia.

Quantitative analysis of the rate of leptin increase in response to hyperinsulinemia was complicated by the circadian
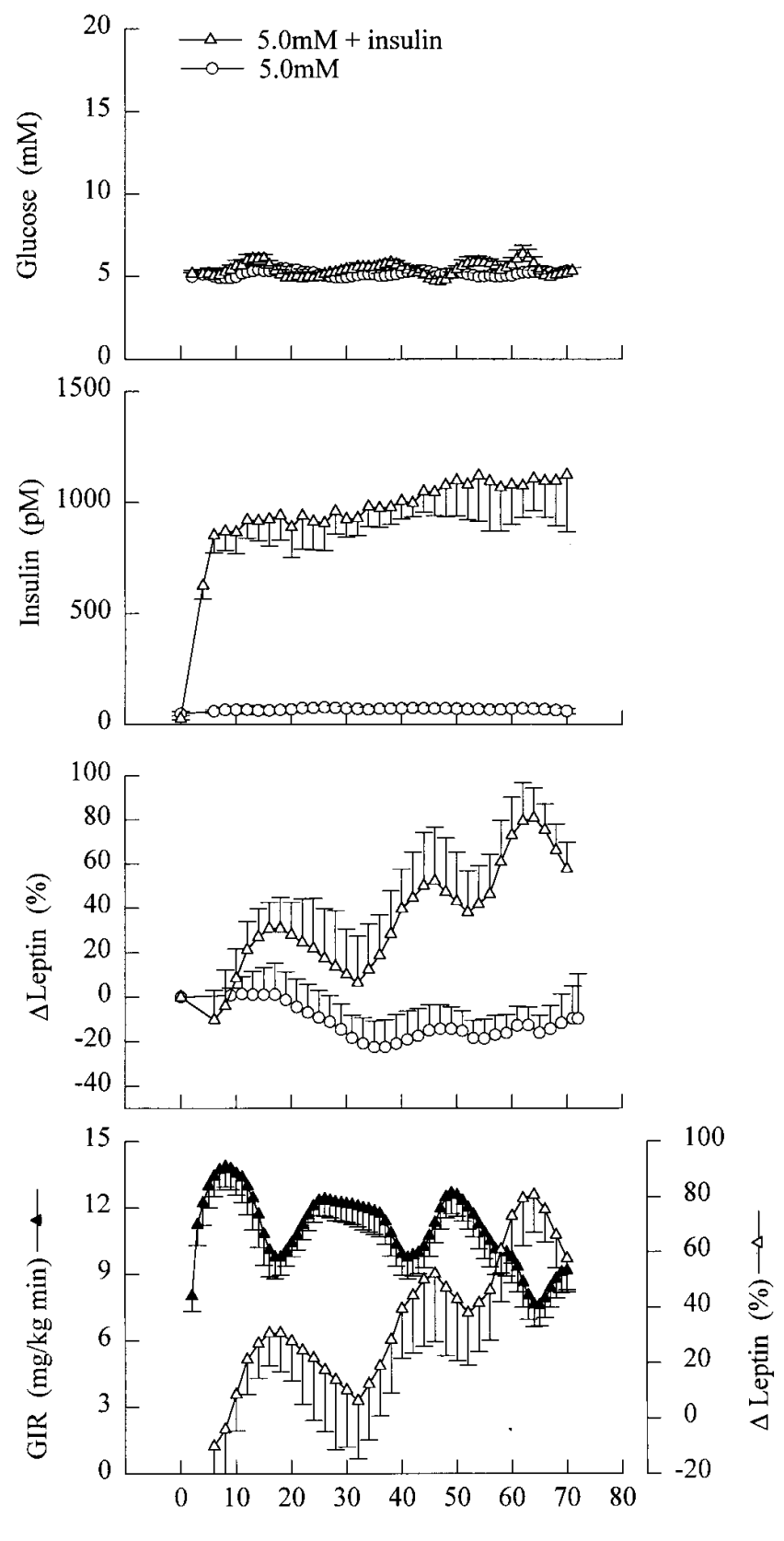

Hours

Figure 1. Effect of hyperinsulinemia on leptin. Glucose concentrations (top), insulin concentrations (second from top), and leptin (in \% of baseline, second from bottom) during $72 \mathrm{~h}$ of euglycemic (protocol $1, n=5$ ) and euglycemic-hyperinsulinemic clamping (protocol 2, $n=5$ ). The bottom shows GIR needed to maintain euglycemia and changes in serum leptin concentrations (in \% of baseline) during euglycemic-hyperinsulinemic clamping (protocol 2). Shown are mean $\pm \mathrm{SE}$ and moving averages (span of range $=4$ ). Serum leptin concentrations at $0 \mathrm{~h}$ were $4.0 \pm 0.8$ (euglycemic clamps) and $3.1 \pm 0.7$ $\mathrm{ng} / \mathrm{ml}$ (euglycemic-hyperinsulinemic clamps).

rhythmicity of leptin secretion (see below). To overcome this problem, we have averaged daily serum leptin concentrations. Correlation of mean 24-h leptin changes (from all five protocols) with changes in serum insulin levels showed that there was no significant rise in serum leptin during the initial $24 \mathrm{~h}$ regardless of the degree of hyperinsulinemia. In addition, a rise 

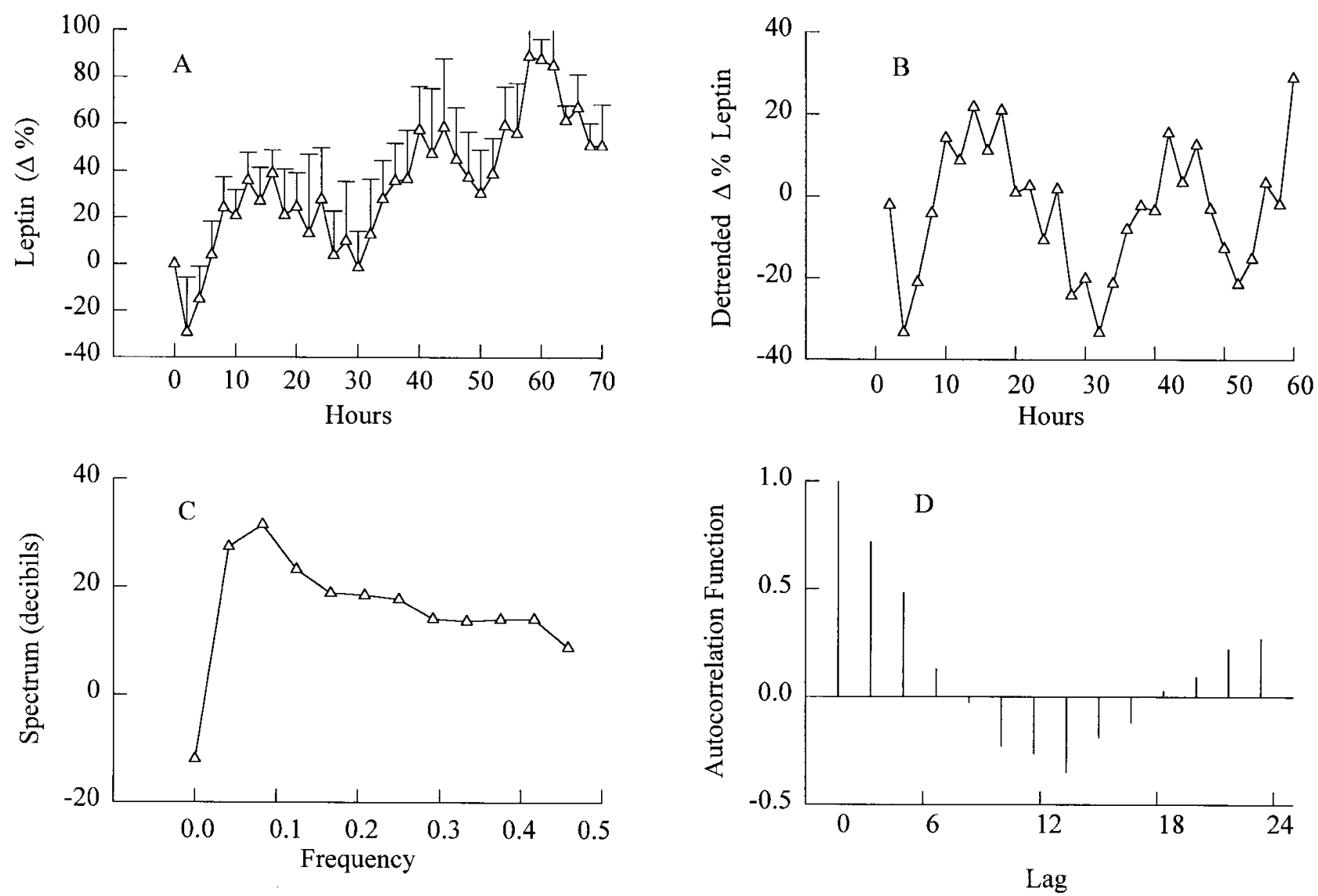

Figure 2. Circadian leptin rhythmicity. (A) Serum leptin levels in percent of baseline during euglycemic-hyperinsulinemic clamping for $72 \mathrm{~h}$. Serum leptin concentration at $0 \mathrm{~h}$ was $3.1 \pm 0.7 \mathrm{ng} / \mathrm{ml}$. $(B)$ The same data as in $A$ detrended by subtracting the slope multiplied by time. The slope was obtained by least square linear regression of the percent leptin changes vs. time using two complete cycles. $(C)$ Spectral analysis estimated by a discrete Fourier transform of the detrended data. $(D)$ The autocorrelation function, i.e., the correlation of the original leptin series with itself as it is progressively shifted down (lagged).

in serum insulin by $\sim 400 \mathrm{pM}$ during lipid/heparin infusion (see Fig. 4) that lasted $\sim 10 \mathrm{~h}$ and that was probably caused by the elevated plasma FFA levels (21), did not affect serum leptin concentrations. After $24 \mathrm{~h}$ and even more so after $48 \mathrm{~h}$, however, there was a significant stimulation of serum leptin levels by insulin (see Fig. 5). The increase appeared to be dosedependent. An increase in serum insulin by $\sim 800 \mathrm{pM}$ (protocol 2) increased serum leptin concentrations by $\sim 70 \%$ over $3 \mathrm{~d}$; an increase of $\sim 200 \mathrm{pM}$ (protocol 3) had no apparent effect on leptin while maintaining basal insulin concentrations for $3 \mathrm{~d}$ (protocol 1) resulted in a slight decrease in leptin levels $(\sim-15 \%)$. Comparable results were obtained comparing daily trough or daily peak leptin levels (during protocols 2 and $5)$. Together, these findings suggested that relatively large increases in serum insulin levels $(>200 \mathrm{pM})$ were needed for relatively long periods of time $(>24 \mathrm{~h})$ before serum leptin levels rose significantly. These results are in accord with reports by several groups, who, with one exception, all failed to find effects of acute (up to $5 \mathrm{~h}$ ) hyperinsulinemia on leptin levels (10-16). The sole exception, a study by Utriainen et al. (16), reported an $\sim 50 \%$ increase in serum leptin after $4 \mathrm{~h}$ of unphysiologic high insulin levels $(\sim 2,800 \mathrm{pM})$. The reason for these discrepant findings is not clear.

Mechanism of the insulin effect on leptin. We next investi- gated the possibility that insulin may have increased serum leptin indirectly through its FFA-lowering effect. We found that neither high $(>1,000 \mu \mathrm{M})$ nor low $(<100 \mu \mathrm{M})$ plasma FFA concentrations affected serum leptin when insulin was maintained at a concentration that by itself had no stimulatory effect ( $\sim 200$ pM, Fig. 4). Our studies cannot rule out other indirect modes of insulin action on leptin, for instance, metabolic processes requiring insulin and glucose such as lipogenesis.

In animals there is strong evidence in favor of direct effects of insulin on ob gene expression (22-26). Dose-dependent stimulation by insulin of ob gene expression has been shown in rat adipocytes in primary culture (22), cultured 3T3-F442A and 3T3-L1 mouse cells $(23,25)$. Furthermore, it has been shown that raising or lowering of plasma insulin concentrations in vivo in rodents resulted in up- or down-regulation, respectively, of leptin mRNA, and that insulin produced a dosedependent rise in leptin release from cultured human fat cells (26). These data support the notion that insulin regulated leptin levels, at least in part, by direct action on ob gene expression.

Leptin levels change with circadian rhythmicity. Analysis of changes in serum leptin over $72 \mathrm{~h}$, by detrending of raw data, the Fourier transform, and the autocorrelation function, revealed circadian rhythmicity with a cycle length of $\sim 24 \mathrm{~h}$ and 

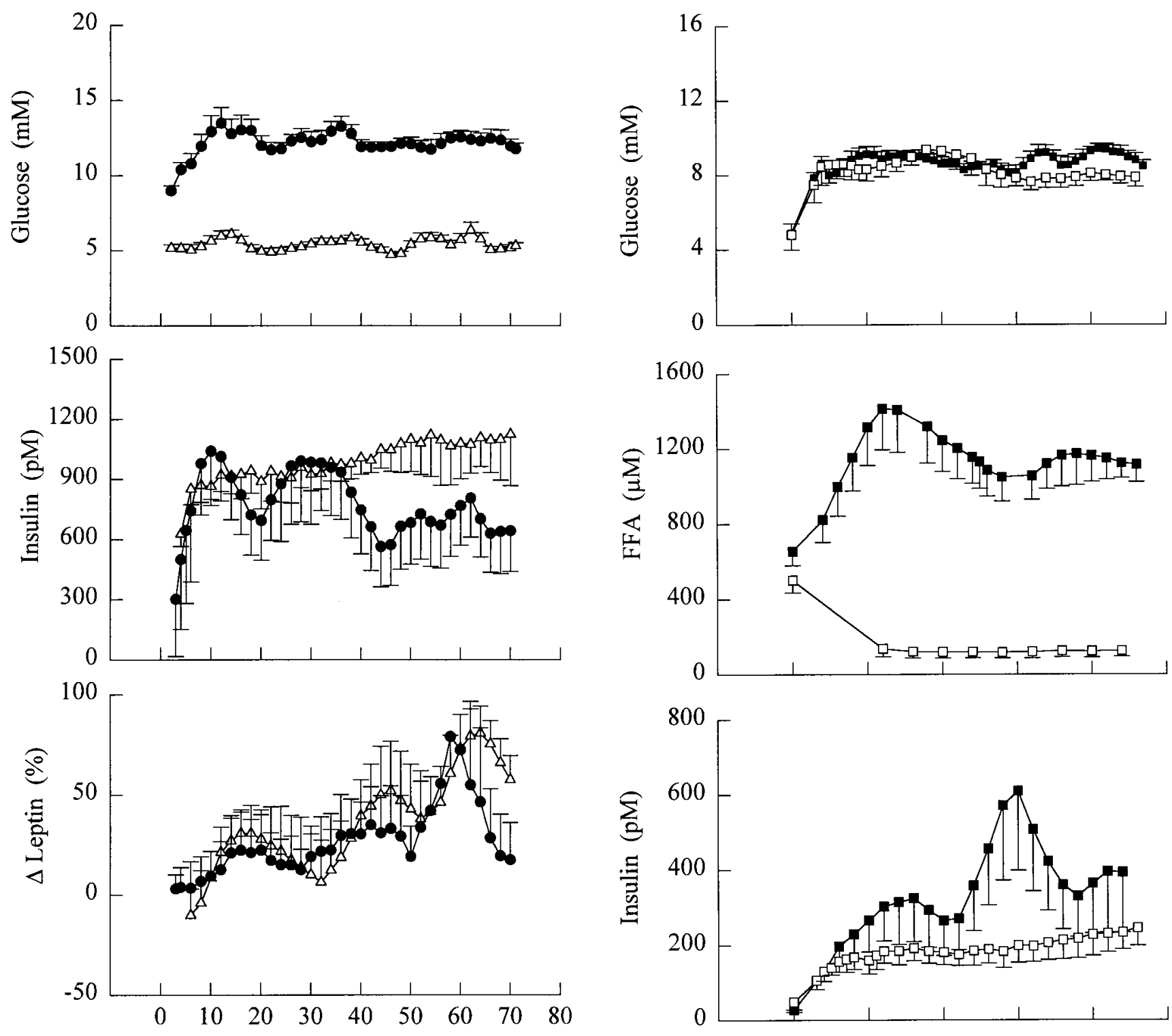

Hours

Figure 3. Effects of hyperglycemia on leptin. Serum glucose and insulin concentrations and leptin changes (in \% of baseline) during $72 \mathrm{~h}$ of euglycemic-hyperinsulinemic and hyperglycemic $(\sim 12.6 \mathrm{mM})$ clamping. Serum leptin at baseline were $3.1 \pm 0.7 \mathrm{ng} / \mathrm{ml}$ (euglycemichyperinsulinemia) and $5.2 \pm 0.6 \mathrm{ng} / \mathrm{ml}$ (hyperglycemic-clamping). Filled circles, $12.6 \mathrm{mM}$; open triangles, $5.0 \mathrm{mM}+$ insulin.

an amplitude of $\sim 50 \%$ (peak to trough). The cycle amplitudes appeared to be related to the level of leptin secretion. Leptin rhythmicity was pronounced at high insulin levels (protocols 1 and 5). When insulin levels were low (protocol 1), leptin rhythmicity was barely visible, and only became evident after Fourier transform (not shown). The most likely reason for this was the lower pulse-to-noise ratio present at low leptin secretion rates (19). Sinha et al. (27) have recently reported a nocturnal rise in serum leptin in lean and obese nondiabetic subjects, and in obese diabetic patients who ate three meals and one snack. These authors were unable to establish circadian rhythmicity because of the shortness of blood sampling. Laughlin and Yen

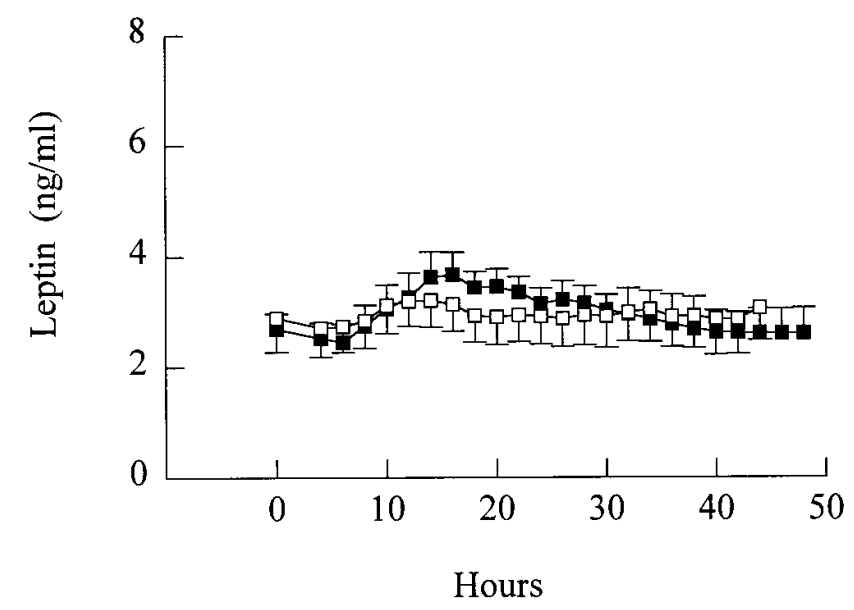

Figure 4. Effects of FFA on leptin. Glucose, FFA, insulin, and leptin concentrations during $48 \mathrm{~h}$ of hyperglycemic $(\sim 8.5 \mathrm{mM})$ clamping with and without infusion of lipid/heparin (Liposyn II, $4.3 \mu \mathrm{mol} / \mathrm{kg}$ min plus heparin $0.4 \mathrm{U} / \mathrm{min}$ ). Serum leptin levels at $0 \mathrm{~h}$ were $2.7 \pm 0.3$ $\mathrm{ng} / \mathrm{ml}$ (lipid) and $2.9 \pm 0.6 \mathrm{ng} / \mathrm{ml}$ (saline). Black squares, lipid; white squares, saline. 

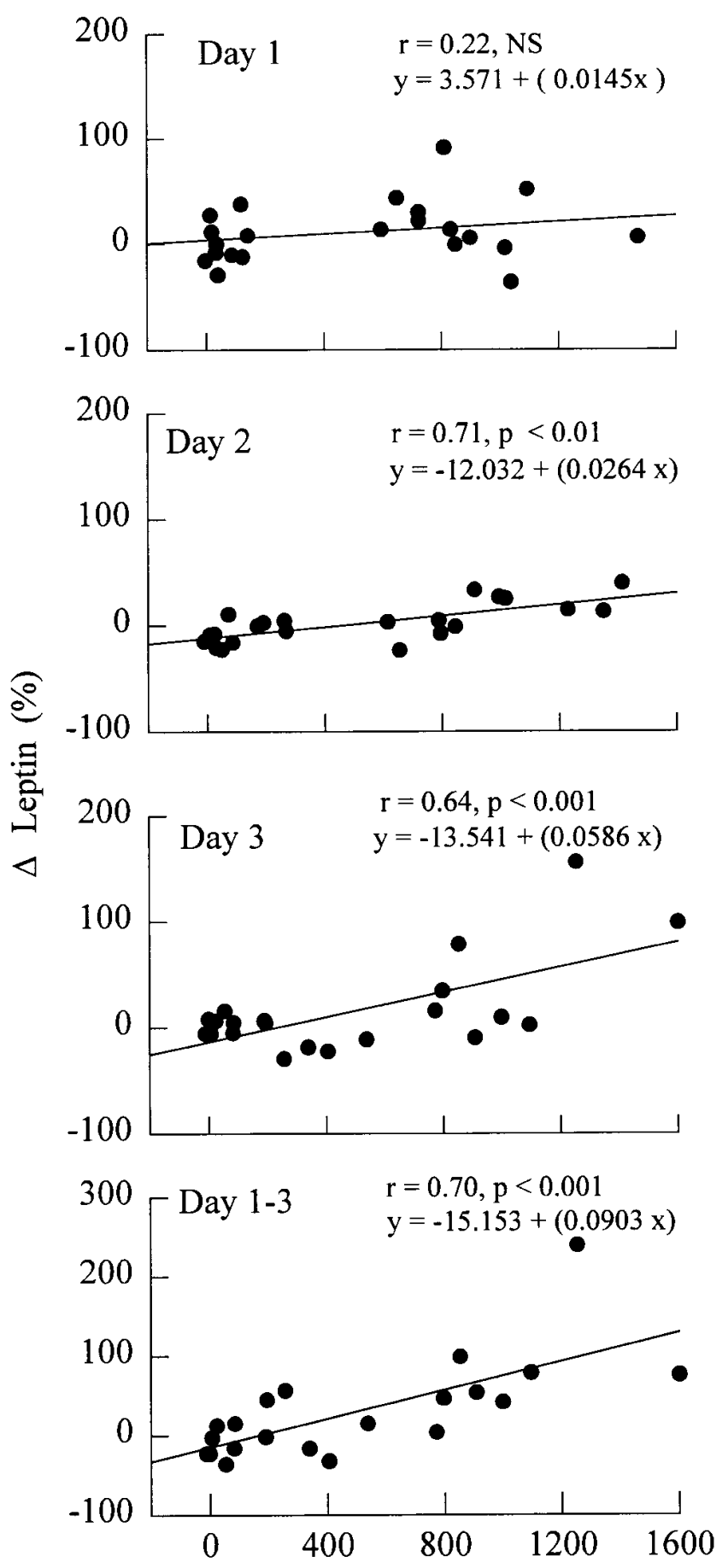

$\Delta$ Insulin $(\mathrm{pM})$

Figure 5. Correlation of changes in mean 24-h leptin concentrations with changes in mean insulin concentrations on days 1,2 , and 3. Day 1 (mean of 0-24 h minus basal leptin or insulin values); day 2 (mean of 25-48 h minus mean of $0-24 \mathrm{~h}$ leptin or insulin values); day 3 (mean of 49-72 h minus mean of 25-48 h leptin or insulin values). Bottom shows correlations of mean $72 \mathrm{~h}$ changes in leptin with insulin. Included are data from all five protocols.

have recently reported diurnal pattern of leptin levels that correlated positively with serum insulin levels in female athletes (28). Blood sampling for $72 \mathrm{~h}$ in this study was sufficiently long to establish circadian rhythmicity; in addition, our studies were not confounded by effects of food intake and physical exercise. On the other hand, effects of the sleep/wake cycle on leptin rhythmicity were not specifically investigated. The observed circadian changes, however, did not seem to be related to changes in the sleep/wake cycle. This was not surprising, as sleep during the night was interrupted every $2 \mathrm{~h}$ by blood collections. Our results, therefore, cannot exclude the possibility that normal uninterrupted sleep may have modulating effects on leptin levels. Neither the cause for nor possible consequences of the circadian rhythmicity of serum leptin levels were investigated and remain uncertain.

We observed, however, that GIR, reflecting peripheral plus hepatic insulin sensitivity, and serum leptin levels, both changed cyclically and in opposite directions (i.e., whenever leptin rose GIR decreased and vice versa). This was compatible with the possibility, but in no way proved, that leptin may have induced insulin resistance.

Insulin, a link between fat mass and leptin. The finding that leptin concentrations decreased with fasting $(7,8)$ and increased during hyperinsulinemia (this study) when changes in adipose tissue mass were trivial, and the demonstration by others that serum leptin levels correlated with changes in plasma insulin levels independent of changes in adiposity $(11,29)$ indicated that the rate of leptin secretion could not have been determined exclusively by the number and/or size of adipocytes. On the other hand, they suggested that chronic alterations in serum insulin levels, such as occur in obesity, may be responsible, at least in part, for the high leptin levels in obesity, and for the positive correlation between body fat mass and leptin levels.

\section{Acknowledgments}

We thank the nurse of the GCRC for excellent patient care, Karen Davis and Maria Mozzoli for outstanding technical assistance, and Constance Harris for typing the manuscript.

This work was supported by National Institutes of Health grants R01-AG-07988, R01-AA-10221 (G. Boden), and RR-349 (General Clinical Research Center) and a mentor-based postdoctoral fellowship grant from the American Diabetes Association (G. Boden).

\section{References}

1. Zhang, Y., R. Proenca, M. Maffei, M. Barone, L. Leopold, and J.M. Friedman. 1994. Positional cloning of the mouse obese gene and its human homologue. Nature (Lond.). 372:425-432.

2. Pelleymounter, M.A., M.J. Cullen, M.B. Baker, R. Hecht, D. Winters, T. Boone, and F. Collins. 1995. Effects of the obese gene product on body weight regulation in ob/ob mice. Science (Wash. DC). 269:540-543.

3. Halaas, J.L., K.S. Gajiwala, M. Maffei, S.L. Cohen, B.T. Chait, D. Rabinowitz, R.L. Lallone, S.K. Burley, and J.M. Friedman. 1995. Weightreducing effects of the plasma protein encoded by the obese gene. Science (Wash. DC). 269:543-546.

4. Campfield, L.A., F.J. Smith, Y. Guisez, R. Devos, and P. Burn. 1995. Recombinant mouse $\mathrm{OB}$ protein: evidence for a peripheral signal linking adiposity and central neural networks. Science (Wash. DC). 269:546-549.

5. Maffei, M., J. Halaas, E. Ravussin, R.E. Pratley, G.H. Lee, Y. Zhang, H. Fei, S. Kim, R. Lallone, S. Ranganathan, et al. 1995. Leptin levels in human and rodent: measurement of plasma leptin and ob RNA in obese and weightreduced subjects. Nat. Med. 1:1155-1161.

6. Considine, R.V., M.K. Sinha, M.L. Heiman, A. Kriauciunas, T.W. Stephens, M.R. Nyce, J.P. Ohannesian, C.C. Marco, L.J. McKee, T.L. Bauer, and J.F. Caro. 1996. Serum immunoreactive leptin concentrations in normalweight and obese humans. N. Engl. J. Med. 334:292-295.

7. Boden, G., X. Chen, M. Mozzoli, and I. Ryan. 1996. Effect of fasting on serum leptin in normal human subjects. J. Clin. Endocrinol. Metab. 81:34193423 .

8. Kolaczynski, J.W., R.V. Considine, J.H. Ohannesian, C. Marco, I. Opentanova, M.R. Nyce, M. Myint, and J.F. Caro. 1996. Responses of leptin to shortterm fasting and refeeding in humans. Diabetes. 45:1511-1515. 
9. Schwartz, M.W., D.P. Figlewicz, D.G. Baskin, S.C. Woods, and D. Porte. 1994. Insulin and the central regulation of energy balance: update 1994. Endocr. Rev. 2:109-113.

10. Kolaczynski, J.W., M.R. Nyce, R.V. Considine, G. Boden, J.J. Nolan, R. Henry, S.R. Mudaliar, J. Olefsky, and J.F. Caro. 1996. Acute and chronic effect of insulin on leptin production in humans. Diabetes. 45:699-701.

11. Segal, K.R., M. Landt, and S. Klein. 1996. Relationship between insulin sensitivity and plasma leptin concentration in lean and obese men. Diabetes. 45: 988-991.

12. Dagogo-Jack, S., C. Fanelli, D. Paramore, J. Brothers, and M. Landt. 1996. Plasma leptin and insulin relationships in obese and nonobese humans. Diabetes. 45:695-698.

13. Ryan, A.S., and D. Elahi. 1996. The effects of acute hyperglycemia and hyperinsulinemia on plasma leptin levels: its relationships with body fat, visceral adiposity, and age in women. J. Clin. Endocrinol. Metab. 81:4433-4438.

14. Pratley, R.E., M. Nicolson, C. Bogardus, and E. Ravussin. 1996. Effects of acute hyperinsulinemia on plasma leptin concentrations in insulin-sensitive and insulin-resistant Pima Indians. J. Clin. Endocrinol. Metab. 81:4418-4421.

15. Caprio, S., W.V. Tamborlane, D. Silver, C. Robinson, R. Leibel, S. McCarthy, A. Grozman, A. Belous, D. Maggs, and R.S. Sherwin. 1996. Hyperleptinemia: an early sign of juvenile obesity: relations to body fat depots and insulin concentration. Am. J. Physiol. 271:E626-E630.

16. Utriainen, T., R. Malmstrom, S. Makimattila, and H. Yki-Jarvinen. 1996. Supraphysiological hyperinsulinemia increases plasma leptin concentrations after $4 \mathrm{~h}$ in normal subjects. Diabetes. 45:1364-1366.

17. Lukaski, H.C., W.W. Bolonchuk, C.B. Hall, and W.A. Siders. 1986. Validation of tetrapolar bioelectrical impedance method to assess human body composition. J. Appl. Physiol. 60:1327-1332.

18. Bloomfield, P. 1976. Fourier Analysis of Time Series: An Introduction. Wiley-Liss, Inc, New York. 1-258.

19. Boden, G., J. Ruiz, J.L. Urbain, and X. Chen. 1996. Evidence for a circadian rhythm of insulin secretion. Am. J. Physiol. 271:E246-E252.
20. Klein, S., S.W. Coppack, V. Mohamed-Ali, and M. Landt. 1996. Adipose tissue leptin production and plasma leptin kinetics in humans. Diabetes. 45:984-987.

21. Boden, G., X. Chen, J. Rosner, and M. Barton. 1995. Effects of a 48-h fat infusion on insulin secretion and glucose utilization. Diabetes. 44:1239-1242.

22. Saladin, R., P. De Vos, M. Guerre-Millo, A. Leturque, J. Girard, B. Staels, and J. Auwerx. 1995. Transient increase in obese gene expression after food intake or insulin administration. Nature (Lond.). 377:527-529.

23. Leroy, P., S. Dessolin, P. Villageois, B.C. Moon, J.M. Friedman, G. Ailhaud, and C. Dani. 1996. Expression of ob gene in adipose cells. Regulation by insulin. J. Biol. Chem. 271:2365-2368.

24. Cusin, I., A. Sainsbury, P. Doyle, F. Rohner-Jeanrenaud, and B. Jeanrenaud. 1995. The ob gene and insulin. A relationship leading to clues to the understanding of obesity. Diabetes. 44:1467-1470.

25. MacDougald, O.A., C.S. Hwang, H. Fan, and M.D. Lane. 1995. Regulated expression of the obese gene product (leptin) in white adipose tissue and 3T3-L1 adipocytes. Proc. Natl. Acad. Sci. USA. 92:9034-9037.

26. Wabitsch, M., P. B. Jensen, W.F. Blum, C.T. Christoffersen, P. Englaro, E. Heinze, W. Rascher, W. Teller, H. Tornqvist, and H. Hauner. 1996. Insulin and cortisol promote leptin production in cultured human fat cells. Diabetes. 45 $1435-1438$.

27. Sinha, M.K., J.P. Ohannesian, M.L. Heiman, A. Kriauciunas, T.W Stephens, S. Magosin, C. Marcho, and J.F. Caro. 1996. Nocturnal rise of leptin in lean, obese, and non-insulin-dependent diabetes mellitus subjects. J. Clin. Invest. 97:1344-1347.

28. Laughlin, G.A., and S.S.C. Yen. 1997. Hypoleptinemia in women athletes: absence of a diurnal rhythm with amenorrhea. J. Clin. Endocrinol. Metab. 82:318-321.

29. Havel, P.J., S. Kasim-Karakas, W. Mueller, P.R. Johnson, R.L. Gingerich, and J.S. Stern. 1996. Relationship of plasma leptin to plasma insulin and adiposity in normal weight and overweight women: effects of dietary fat content and sustained weight loss. J. Clin. Endocrinol. Metab. 81:4406-4413. 